\title{
Quantificação da microbiota e diversidade ecológica da meso e macrofauna do solo sob diferentes usos no município de Urutaí (região Sudeste Goiano)
}

\author{
Franciele Cristina da Silva ${ }^{1}$, Ígor de Jesus Santana ${ }^{1}$, Rodolfo David Martins ${ }^{1}$, Natanael Marcos Lemes ${ }^{1}$, Anderson \\ Rodrigues Rietjens ${ }^{1}$, Milton Luiz da Paz Lima2* \\ ${ }^{1}$ Instituto Federal Goiano - Campus Urutaí, GO, Brasil. \\ 2Programa de Pós-Graduação em Proteção de Plantas, Instituto Federal Goiano - Campus Urutaí, GO, Brasil. *Autor para correspondência: \\ fitolima@gmail.com
}

\section{N F O A R T I G O}

\section{Histórico do artigo}

Recebido: 10 julho 2015

Aceito: 12 agosto 2015

\section{Palavras chaves:}

Usos de solo

Riqueza de grupos taxonômicos

Unidade formadora de colônia

\begin{abstract}
A B S T R A C T
The soil fauna exerts strong influence on the rhizosphere and soil microbial activity playing a key role in biodiversity conservation. The objective of this work was the presentation of methodologies used and characterize the ecological diversity of the microbiota, meso and macrofauna in soils under different uses. Two methodologies were conducted in a completely randomized design in the field, with five repetitions on each type of land use, constituting the treatments: 1) anthropic Forest; 2) Fruticultura; 3) Vegetable Crops; 4) Fish farming and 5) eucalyptus cultivation. Soil samples were collected for quantification of soil microbiota (colony forming units per gram. - UFC g-1 soil) in repetitions using the dilution method in series. It adopted the method of pitfall traps type (pitfall traps) to quantify the abundance of meso and macrofauna. The abundance values were used to calculate the following parameters: Chao indices, Shannon, Simpson and Fisher. In the first method we evaluated the number of CFU. g- ${ }^{-1}$ soil and second methodology plenty of orders or taxonomic groups of animals. The dependent variables were analyzed using ANOVA and Tukey test. It was increased the number of CFU. $\mathrm{g}^{-1}$ soil in use in Vegetable Crops, differing from other statistically. It found most populous in soils belonging to the order Hymenoptera. The use of soil with eucalyptus planting statistically richer taxonomic groups, with no significant difference in land use for the Shannon index parameter, Fisher and Simpson. The impact of the actions promoted by man can be translated by the implementation of methodologies to describe and reflect through number of parameters and diversity ecological relationships resulting from land use.
\end{abstract}

\section{Introdução}

O solo é um sistema complexo que comporta em sua estrutura elementos bióticos dinamizantes na organização de suas partículas e na decomposição de resíduos orgânicos. A fauna edáfica propicia a continuidade ao funcionamento apropriado deste ecossistema através da sua atuação na proteção do solo contra erosão, filtragem de ar e água, e na manutenção da cadeia alimentar e do fluxo energético de seu habitat. Fatores como o melhoramento da mobilização de nutrientes através de enzimas, a atuação na distribuição do material orgânico e movimentação mecânica do solo e ativação do metabolismo dos microrganismos do solo podem ser afetados pela diversidade biológica. (Antoniülli et al., 2006;
Lourente et al., 2007; Primack \& Rodrigues, 2001; Primavesi, 2002).

O solo pode ser considerado o centro principal de organização dos ecossistemas terrestres, pois, em sua grande parte, os nutrientes são ciclados durante a decomposição da matéria orgânica (MO) antes de se tornarem disponível para as plantas. Ele não é apenas um fator do ambiente para os organismos, mas também é produzido por eles e, de modo geral, é o resultado líquido da ação do clima e dos organismos (microrganismos, micro, meso, macro e megafauna e vegetação) sobre a rocha-matriz na superfície da Terra (Odum, 2008). 
A biomassa microbiana, que representa a parte viva da matéria orgânica do solo, atua nos processos biogeoquímicos do solo. Ela é composta por bactérias, fungos e representantes da microfauna, que participam de importantes funções do solo, como a ciclagem de nutrientes e energia, regulando as transformações da matéria orgânica, controle biológico de pragas e doenças (Turco et al., 1994; Moreira \& Siqueira, 2002).

As armadilhas de queda do tipo pitfall, utilizadas para estudos de diversidade, são destinadas para animais que habitam o solo, caminhando sobre ele ou passam alguma fase de sua vida em sua superfície (Aquino et al., 2006). Desta forma, o tamanho do recipiente coletor, a presença ou não de isca atrativa, a presença de líquido conservante, cerca guia, cobertura e outras estratégias, vão depender da finalidade e do objetivo da captura. A utilização de armadilhas para o monitoramento de organismos tem sido uma prática cada vez mais constante nas áreas exploradas pelo homem (Santos et al., 2012). Segundo Rodrigues et al. (2003), o método de avaliação utilizando armadilhas do tipo pitfall é mais eficaz que o método de observação visual, pois proporciona a coleta e identificação de uma maior quantidade de indivíduos e espécies de predadores que habitam e circulam na superfície do solo.

Dentro da fauna do solo há os organismos macroscópicos representados principalmente pelos invertebrados, que agem como predadores, detritívoros, decompositores de MO e parasitas de plantas e animais (Edwards, 1991). Alexander (1964) apontou que esses componentes da microbiomassa do solo modificam o ambiente físico-químico, mas pouco contribui para os processos biológicos do solo. Essas alterações regulam diversos processos na cadeia trófica e influenciam a atividade microbiana (Gunn \& Cherrett, 1993; Lavelle et al., 1993), e por essas atividades realizadas podem atuar no processo de análise do impacto causado por distúrbios ecológicos promovidos pelo uso do solo no ecossistema, servindo como indicadores biológicos (Fitter et al., 1985; Villani \& Wright, 1990).

Existem várias formas de classificar a biota do solo. 0 tamanho corporal geralmente é o critério básico, pois apresenta alguma relação com o tamanho do tubo digestivo e do aparelho bucal, mas também são levados em consideração aspectos da mobilidade, hábito alimentar e função que desempenham no solo (Silva \& Amaral, 2013). Podem ser classificados de acordo com o seu tamanho, onde os indivíduos da macrofauna são maiores que quatro milímetros e tem como características construir ninhos, cavidades, galerias e transportar materiais de solo; como exemplares dessas características, os anelídeos, térmitas e formigas, além dos moluscos, crustáceos e aracnídeos (Lavelle et al., 1994). A mesofauna compreende invertebrados com diâmetro do corpo inferior a dois milímetros. Habita os espaços porosos do solo, não sendo capaz de criar suas próprias galerias, sendo, desta maneira, afetada pela compactação do solo (Aquino et al., 2006). Atuam principalmente na decomposição da MO, além da geração de húmus e enriquecimento com minerais (Primavesi, 2002).

As populações de organismos da meso e macrofauna podem ser influenciadas através das atividades realizadas no ambiente, como adubação, calagem e o sistema de cultivo utilizado. Também podem ocasionar diferenças significativas na fauna do solo disposta sob diferentes coberturas vegetais e suas práticas de manejo e cultivo, como observado por Barros et al. (2001) que após o desmatamento, a diversidade de macro invertebrados foi reduzida.

Considerando que a biodiversidade de espécies está relacionada com a quantidade de espécies e a quantidade de indivíduos entre as espécies, utilizam-se alguns índices que descrevem a diversidade de comunidades: índices de Simpson e de Shannon, Riqueza de grupos taxonômicos e índice de Fisher.
O método Chao, estima a riqueza de grupos taxonômicos, sugerindo que espécies raras e diversificadas possuem um maior peso. No índice de Shannon outro parâmetro de diversidade aplicado para estudos de diversidade em armadilhas de queda avalia-se a heterogeneidade, valoriza a abundância, ou seja, valoriza as espécies comuns e frequentes em uma comunidade; o índice de Simpson baseia-se na proporção entre os indivíduos, atendo-se à probabilidade de que dois indivíduos tomados aleatoriamente da comunidade pertençam à mesma espécie ou grupo taxonômico (Catanozi, 2011), ou seja, analisa a dominância.

0 índice de Fisher é analisado em relação à quantidade de espécies ou grupo taxonômico representado por apenas um indivíduo na comunidade. Whittaker (1977) atribui ao conceito de riqueza de grupos taxonômicos, como a quantidade de espécies ou grupo taxonômico amostrados na comunidade, o que poderia ser uma definição de diversidade. Medidas de diversidade resultantes de índices podem servir como indicadores do equilíbrio/ desiquilíbrio de sistemas ecológicos (Scolforo et al., 2008).

Os componentes microbianos vivos do solo são também denominados de biomassa microbiana e as bactérias e fungos respondem por cerca de $90 \%$ da atividade microbiana do solo (Andreola \& Fernandes, 2007). 0 solo possui uma imensa diversidade da microbiota, sendo as principais atividades dos organismos a decomposição da MO, produção de húmus, ciclagem de nutrientes e energia (incluindo a fixação de nitrogênio atmosférico), produção de compostos complexos que contribuem para a agregação do solo, decomposição de xenobióticos e controle biológico de pragas e doenças (Moreira \& Siqueira, 2006).

A contagem de unidades formadoras de colônias (UFC) é uma técnica amplamente utilizada em diversos tipos de estudos sobre microbiota do solo. Essa técnica tem como intuito estimar a densidade populacional dos microrganismos no solo (Souto et al., 2008). Esse método revela a quantidade de microrganismos capazes de se multiplicar e formar colônias, presentes no solo através do cultivo sob condições adequadas de nutrição (Antonini, 2004). A contagem de UFC permite a caracterização da biomassa microbiana, assim como avaliar a interferência de parâmetros físico-químicos e biológicos através da distribuição das diferentes populações microbianas e suas especificidades (Hungria \& Araujo, 1994).

Esta pesquisa tem como objetivo a apresentação de metodologias utilizadas para quantificação da microbiota e determinação da diversidade ecológica, da meso e macrofauna em solos com diferentes usos localizados no município de Urutaí, GO.

\section{Material e Métodos}

0 experimento foi desenvolvido no ano de 2015, no Instituto Federal Goiano - Campus Urutaí, localizado no município de Urutaí, GO, sob as coordenadas $17^{\circ} 28^{\prime} 41^{\prime \prime S}$ e 4811'35" O e altitude de $800 \mathrm{~m}$. O tipo climático é Aw, segundo classificação de Köppen, caracterizado com duas estações bem definidas, verão chuvoso e inverno seco. Com temperaturas médias mínimas de 16 a 20 ํ C e máximas de 32 a $36^{\circ} \mathrm{C}$, e acúmulo de chuva médio de 250 milímetros.

A coleta de solo (estudo da microbiota) e instalação de armadilhas (estudo da meso e macrofauna) foi realizada na Fazenda Palmital, inserida no bioma Cerrado, no período chuvoso de março de 2015, em solos com os usos representados por: 1) Floresta Antropizada (4,7 ha); 2) Fruticultura (1,72 ha); 3) Olericultura (0,97 ha); 4) Piscicultura (2,9 ha) e 5) Cultivo de eucalipto (3,3 ha). A Floresta antropizada apresentava o tipo fitofisionômico denominado de mata de galeria, além dos demais usos do solo antes da antropização. O delineamento foi inteiramente casualizado, com cinco repetições para cada tipo de uso de 
solo. Foram determinados aleatoriamente os locais para a coleta das amostras de solo e instalação das armadilhas pitfall. Metodologia para quantificação de microbiota.

Para cada amostragem com pá na profundidade de $20 \mathrm{~cm}$ foram coletadas, aproximadamente, $100 \mathrm{~g}$ de solo da profundidade de $0-20 \mathrm{~cm}$. Foi realizada a limpeza da ferramenta com água em cada amostra e uso de solo diferente. Cada uma das cinco amostras (pernoite a $15^{\circ} \mathrm{C}$ ) por uso de solo foram identificadas e individualizadas em uma embalagem plástica, representados por cinco usos do solo, cinco repetições, totalizando 25 amostras para quantificação do crescimento de fungos e bactérias pela técnica da "Diluição em série" (sensu Madigan et al., 2010).

Iniciou-se a pesagem das amostras em balança de precisão coletando-se um grama de solo homogeneizado por amostra, transferindo-se para um tubo de ensaio, contendo nove milímetros de água destilada autoclavada produzindo a concentração de [10-1]. Foi realizada a diluição nas concentrações de $10^{-1}, 10^{-2}, 10^{-3}$ e $10^{-4}$, sendo que cada tubo de ensaio continha nove milímetros de água destilada autoclavada.

As amostras foram agitadas durante um minuto em um agitador mecânico, em seguida um milímetro da solução foi transferido para outro tubo de ensaio contendo nove milímetros de água destilada estéril, resultando na diluição de $10^{-2}$, sendo agitada conforme descrito para a anterior. As demais diluições foram obtidas da mesma forma.

Utilizaram-se apenas as concentrações de $10^{-3}$ e 104 (escolhidos devido à contagem facilitada de UFC) para plaqueamento em meio de cultura nutriente ágar (NA). Em cada placa de Petri (duas repetições por diluição; quatro repetições por amostra de solo para que tenham amplitude de valor numérico) foram adicionados ao centro com micropipeta de $50 \mu \mathrm{L}$ das diluições, sendo essas espalhadas com alça de Drigalski.

As placas permaneceram sob incubação em câmara de crescimento a $25{ }^{\circ} \mathrm{C}$ por um período de 48 horas A quantificação das colônias foi realizada após decorridas 24 e 48 horas.

Metodologia para quantificação de macro e mesofauna.

Utilizando a metodologia pitfall (sensu Almeida et al., 2003), escavou-se o solo com dimensões de 5,5 x $15 \mathrm{~cm}$ (diâmetro x profundidade) para inserção de uma garrafa plástica com capacidade para $600 \mathrm{~mL}$, com fundo recortado e com sua parte superior voltada para o solo, e o fundo disposto à superfície sendo nivelado com o solo. Foram montadas cinco armadilhas para cada uso de solo, enterradas no solo, foram adicionados $200 \mathrm{~mL}$ da solução preservante (álcool: água na proporção de 1:1, adicionando 10 gotas de Tween 20) por um período de sete dias. Protegeu-se a armadilha de possíveis chuvas com uma bandeja de isopor localizada $a$, aproximadamente, $20 \mathrm{~cm}$ de altura da abertura da armadilha.

Estaqueou-se o ponto de instalação da armadilha, identificando-o, procedendo-se, assim, para cada uma das cinco repetições, para cada um dos cinco tratamentos (usos de solo selecionados), totalizando 25 armadilhas ou unidades experimentais.

Após sete dias, as armadilhas foram retiradas, e as amostras foram separadas em sua ordem de abundância. Em laboratório, a solução preservante de cada armadilha foi coada, lavada com água corrente e a meso e macrofauna foram coletadas e separadas em ordem de similaridades num "papel borrão" com formato quadrado. Cada amostra foi seca com papel toalha, separada com pinça, e quantificada quanto à abundância de ordens ou grupos taxonômicos da fauna por amostras, por tratamento.

\section{Análise dos dados}

Avaliou-se a quantidade de unidades formadoras de colônias por grama (UFC.g-1) de solo úmido após 24 e 48 horas, sendo esta a variável dependente para estudo da microbiota do solo. Utilizando os valores de abundância de espécies quantificadas, foram calculados, com o uso do software "Spade" a estimativa da Riqueza de grupos taxonômicos (método Chao), e os Índices de Shannon, Simpson e de Fisher, sendo estas as variáveis dependentes que avaliam a quantificação de macro e mesofauna nos diferentes usos de solo estudados.

A quantidade de UFC.g- ${ }^{-1}$ de solo (microbiota), a abundância de espécies e os parâmetros de diversidade (macro e mesofauna) calculados foram transformados por $\sqrt{(x+10)}$ a fim de normalizar o conjunto de dados. Utilizando o programa Assistat ${ }^{\circledR}$, as variáveis dependentes transformadas foram submetidas à análise de variância (ANOVA) e teste de comparação de médias de Tukey a $5 \%$ de probabilidade.

\section{Resultados e discussão \\ Quantificação da microbiota}

A maior quantidade de unidades formadoras de colônia (UFC. ${ }^{-1}$ ) de solo foi observada num solo cultivado com olerícolas, diferindo estatisticamente dos demais tratamentos. Em horticultura, devido ao cultivo intensivo, e o desenvolvimento de vários ciclos da cultura, há uma constante incorporação de resíduos orgânicos, maior quantidade de húmus, e adição de adubos orgânicos, além dos procedimentos de preparo e revolvimento do solo que melhoram suas condições de porosidade e aeração, permitindo melhoria do crescimento e desenvolvimento de populações microbianas (Filgueira, 2000; Peacock et al., 2001; Moreira \& Siqueira, 2006).

A estrutura da comunidade microbiana do solo em decorrência do uso de insumos orgânicos (fezes, urina e cama de gado), e a aplicação de adubos minerais por vários anos, resultou em um aumento nos teores de $\mathrm{C}$ orgânico e $\mathrm{N}$, e na biomassa microbiana nos solos analisados (Peacock et al., 2001).

Um solo com elevado teor de MO tende a manter a população microbiana mais estável, em decorrência da riqueza de nichos ecológicos, pela heterogeneidade das fontes de C (De Fede et al., 2001; Grayston et al., 2001).

A rotação de cultura pode indicar plantas com afinidades com grupos específicos de microrganismos favorecendo a diversidade o aumento populacional; o revolvimento do solo auxilia no aumento da aeração, que proporciona a proliferação de microrganismos mineralizadores. Quando o solo apresenta alto conteúdo de MO e densa massa radicular, a existência de grande biomassa microbiana na rizosfera amplia-se (Alvarenga et al., 1999).

Após 24 horas o número de UFC.g-1 nos diferentes usos de solo (Figura 2), demonstrou que no uso de Floresta de Galeria Antropizada apresentou estatisticamente menores valores. Comparativamente com outros usos de solo a menor concentração indica que o consórcio com gado tem provocado distúrbios na quantidade de propágulos microbianos ativos.

A pequena quantidade de MO no local, e seu uso em superpastejo, o excesso de animais ocasionou uma sedimentação e redução da densidade, diminuindo a infiltração da água, causando aceleração na degradação do solo, reduzindo a quantidade de biomassa, e as consequências físicas são redução da presença de oxigênio difundido, porosidade total, macroporosidade, permeabilidade e infiltração, prejudicando consequentemente a multiplicação microbiana (Soane \& Ouwerkerk, 1994).

A agricultura sem o emprego de práticas conservacionistas atua negativamente sobre a população microbiana, sendo potencializada pelos fatores edafoclimáticos. Dentre esses, a umidade tem grande expressão na atividade e proliferação microbiana (Berg, 2000). Não somente atributos físicos e edafoclimáticos evidenciam a degradação dos solos, pois segundo Wardle 
(1992), atributos químicos e também variáveis climáticas, considerados em conjunto, quase sempre são capazes de explicar a variação global das atividades (pastejo e cultivo), interferindo diretamente ou indiretamente na diminuição da microbiota do solo e consequente degradação do solo.

Os valores obtidos nos usos de solos com Fruticultura, Olericultura, Piscicultura e cultivo de Eucalipto, quanto ao uso do solo, foram estatisticamente maiores e iguais com relação ao número de UFC.g-1 em solos avaliados após 48 horas, diferindo estatisticamente do uso em floresta antropizada (Figura 1). As variações da quantidade de UFC em solos cultivados com espécies perenes estão diretamente relacionadas ao regime hídrico e ao clima da região, à estrutura e ao manejo do solo, ao teor e à qualidade dos resíduos vegetais aportados, como também foi descrito por Rogers \& Tate III (2001) e Tiedje et al. (2001).

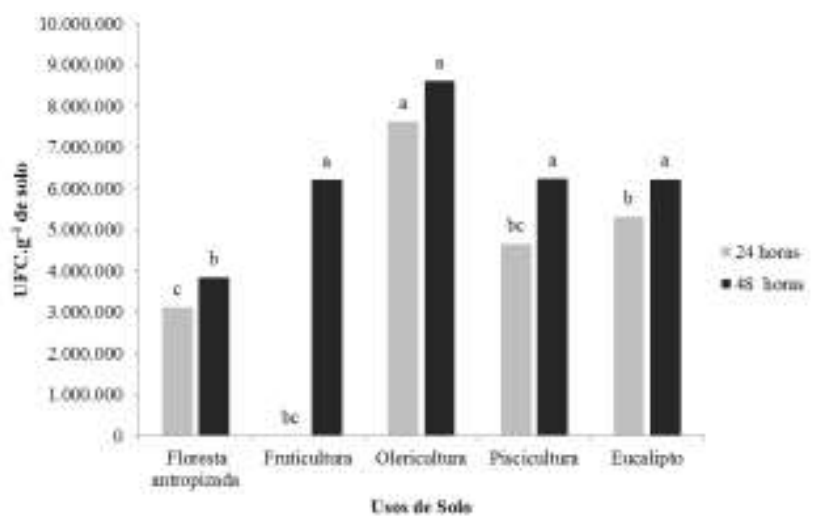

Figura 2: Médias dos valores de unidades formadoras de colônia (UFC. $g^{-1}$ de solo) após 24 e 48 horas de incubação em meio nutriente ágar. Valores seguidos de mesma letra não diferem entre si, pelo teste de Tukey probabilidade a $5 \%$.

\section{Quantificação de macro e mesofauna.}

Nas armadilhas pitfall, foram capturadas insetos de 12 ordens, destacando-se a ordem Hymenoptera, com a maior abundância ou quantidade de organismos capturados (Tabela 1), apresentando relevância e importância agrícola, por serem considerados organismos bioindicadores, uma vez que os insetos são muito importantes na ecologia dos ecossistemas naturais, podendo ser utilizados em estudos de perturbação ambiental (Rosenberg et al., 1986). Destaca-se, também, a ordem Coleoptera, que apresentou expressiva abundância em todos os usos de solo analisados.

Os coleópteros também são excelentes organismos para avaliar o impacto da formação de fragmentos florestais, pois são altamente influenciados pela heterogeneidade do habitat (Thomanzini \& Thomamzini, 2000). Portanto, há razões para que os insetos sejam utilizados em inventários faunísticos em áreas agrícolas.

Na maioria, as espécies são predadoras generalistas e, assim, seus grupos taxonômicos são considerados como sendo organismos benéficos na sustentabilidade ecológica; facilidade de coleta com armadilhas do tipo pitfall e, ainda, porque a maioria dos habitats contém alta quantidade de espécies, permitindo a padronização estatística (Duelli et al., 1999). Porém, muitos destes organismos, principalmente quando estão em elevadas quantidades por espécies, podem ser prejudiciais, provocando um desequilíbrio ecológico (comportamento de praga).

$\mathrm{Na}$ área de uso de solo com Olericultura observou-se o desequilíbrio devido ao fato da ocorrência de maior abundância de formigas, caracterizando esses organismos como sendo "praga" nesse local. As formigas são relatadas, frequentemente, como o grupo mais abundante no solo em estudos sobre a mesofauna (Toledo, 2003; Silva, 2005). Essas são consideradas um dos principais agentes na fragmentação mecânica da serapilheira (Moreira e Siqueira, 2006) e na incorporação da M.O. no solo (Poggiani \& Monteiro, 1990), sendo responsáveis pela aeração do solo, aumentando a infiltração e as trocas gasosas (Gassen, 1999).

Tabela 1. Quantidade de indivíduos de diferentes ordens observados no solo dos tratamentos avaliados, na Fazenda Palmital, do Instituto Federal Goiano, Campus Urutaí, no munícipio de Urutaí, GO (2015).

\begin{tabular}{|c|c|c|c|c|c|}
\hline \multirow[b]{2}{*}{ Ordens } & \multicolumn{5}{|c|}{ Usos de solo } \\
\hline & $\begin{array}{c}\text { Floresta antropizada } \\
(4,7 \text { ha })\end{array}$ & $\begin{array}{c}\text { Fruticultura } \\
(1,72 \text { ha })\end{array}$ & $\begin{array}{c}\text { Olericultura } \\
(0,97 \text { ha) }\end{array}$ & $\begin{array}{c}\text { Piscicultura } \\
(2,9 \text { ha })\end{array}$ & $\begin{array}{c}\text { Cultivo eucalipto } \\
(3,3 \text { ha })\end{array}$ \\
\hline Coleoptera (besouros) & 12 & 79 & 105 & 58 & 80 \\
\hline Hemiptera (percevejos, cigarrinhas, baratas d' água ) & 0 & 0 & 3 & 0 & 6 \\
\hline Hymenoptera (vespa, formiga, abelhas) & 31 & 53 & 3064 & 298 & 66 \\
\hline Diptera (mosca, mosquito) & 0 & 0 & 2 & 0 & 0 \\
\hline Orthoptera (grilo, gafanhoto, paquinha) & 16 & 35 & 5 & 7 & 7 \\
\hline Lepidoptera (mariposa,borboletas, lagartas) & 0 & 3 & 1 & 1 & 1 \\
\hline Anura (perereca, rã) & 0 & 2 & 1 & 1 & 0 \\
\hline Blattodea (baratas) & 0 & 0 & 8 & 2 & 0 \\
\hline Isoptera (cupins) & 0 & 0 & 0 & 15 & 0 \\
\hline Dermaptera (tesourinha) & 2 & 0 & 0 & 0 & 10 \\
\hline Araneae (aranhas) & 0 & 6 & 8 & 5 & 6 \\
\hline Isopoda (tatuzinhos) & 0 & 0 & 0 & 0 & 2 \\
\hline Abudância & 61 & 178 & 3195 & 387 & 178 \\
\hline Total de grupos & 4 & 6 & 8 & 8 & 8 \\
\hline
\end{tabular}


Tabela 2. Valores médios transformados por $\sqrt{(x+10)}$ para Riqueza de Espécies, índice de Shannon, índice de Simpson e índice de Fisher, obtidos no solo dos diferentes tratamentos avaliados, na Fazenda Palmital, do Instituto Federal Goiano, Campus Urutaí, no munícipio de Urutaí-Go, 2015*

\begin{tabular}{lcccc}
\hline & & \multicolumn{2}{c}{ Índices de Diversidade } \\
Us os de solo & Riqueza de Espécies & Índice de Shannon & Índice de Simps on & Índice de Fisher \\
\hline Floresta Antropizada & $4,79780 \mathrm{ab}$ & $3,32260 \mathrm{a}$ & $3,20540 \mathrm{a}$ & $3,46420 \mathrm{a}$ \\
Fruticultura & $3,93640 \mathrm{~b}$ & $3,32520 \mathrm{a}$ & $3,23000 \mathrm{a}$ & $3,37420 \mathrm{a}$ \\
Olericultura & $4,70460 \mathrm{ab}$ & $3,26860 \mathrm{a}$ & $3,26100 \mathrm{a}$ & $3,40280 \mathrm{a}$ \\
Piscicultura & $4,36160 \mathrm{ab}$ & $3,28160 \mathrm{a}$ & $3,25840 \mathrm{a}$ & $3,41620 \mathrm{a}$ \\
Cultivo eucalipto & $4,90040 \mathrm{a}$ & $3,36420 \mathrm{a}$ & $3,01520 \mathrm{a}$ & $3,56060 \mathrm{a}$ \\
\hline Valor de F & $3,26^{*}$ & $1,46^{\mathrm{ns}}$ & $1,26^{\mathrm{ns}}$ & $2,04^{\mathrm{ns}}$ \\
CV\% & $10,73 \%$ & $2,13 \%$ & $6,38 \%$ & $3,32 \%$ \\
\hline
\end{tabular}

* Valores seguidos de mesma letra nas colunas, não diferem entre si pelo teste Tukey a 5 \% de probabilidade; CV= coeficiente de variação.

A riqueza de grupos taxonômicos corresponde à densidade de espécies, tratando-se da quantidade total de espécies em uma dada área ou volume em relação à quantidade de indivíduos ou de comunidades (Catanozi, 2011), ou seja, quanto maior a quantidade de espécies maior a riqueza de uma comunidade.

Observa-se, na Tabela 2, que o solo que apresentou maior riqueza de grupos taxonômicos foi o com uso de cultivo de Eucalipto, cujas médias não diferiram estatisticamente com o uso através da Floresta Antropizada, Olericultura, Piscicultura e Fruticultura.

O tipo de exploração agrícola e a presença de diferentes habitats nas proximidades das culturas podem alterar a diversidade e a abundância de organismos da macro e mesofauna. A quantidade de organismos do solo frequentemente diminui com as práticas agrícolas, incluindo as áreas de pastagens, quando comparado com a população desses organismos em solo recoberto com vegetação natural, devido ao uso de agrotóxicos, operações de preparo do solo, entre outros (Stork \& Eeggleton, 1992; Paoletti, 1999; Bruyn, 1999).

A cobertura vegetal no jardim clonal de eucalipto implantado há cinco anos, assim como Alves et al. (2006), indicou que a ausência de preparo do solo, abundância de cobertura no sistema de plantio e o maior tempo de implementação proporcionaram maior diversidade da fauna edáfica.

Portanto, as intervenções na cobertura vegetal promoveram alterações na densidade e na diversidade da fauna do solo (Azevedo et al., 2000) de forma a mater as populações em desequilíbrio gerando o desaparecimento de determinados grupos (possíveis predadores) em função da relação interdependente da fauna edáfica e da diversidade de recursos, indicando a ocorrência de problemas ambientais (Brown, 2001). As diferentes coberturas vegetais atuam diretamente na população da fauna edáfica, pois alteram a deposição de resíduos orgânicos dispostos sobre a superfície do solo, além de modificarem seus fatores físico-químicos (Antoniulli et al., 2006).

Não houve diferença estatística entre os valores dos cinco tratamentos, representados por Floresta antropizada, Fruticultura, Olericultura, Piscicultura e Cultivo de eucalipto para os índices de Shannon, Simpson e Fisher. Grupos funcionais da fauna edáfica podem desaparecer, ou serem reduzidos, em sua abundância e diversidade, como resultado de processos de degradação do solo (Lavelle, 1996; Loranger et al., 1999). Os padrões de abundância, ou seja, quando uma comunidade apresenta valores menores, representa que este é menos uniforme, sendo mais acentuada a dominância de um ou mais grupos (Begon et al., 1996)

\section{Conclusões}

Os resultados obtidos permitiram concluir, de acordo com as condições experimentais, que:

0 meio pode influenciar na quantidade e na diversidade dos microrganismos presentes, evidenciando a importância de conhecer esses fatores que interferem na quantidade e na presença de organismos do solo.

Solos de cultivo intensivo onde há uma maior quantidade de MO, umidade e alto teor de cobertura vegetal, propiciaram condições favoráveis aos microrganismos.

0 solo da Floresta antropizada e o método de quantificação microbiana sinalizam que o atual manejo está interferindo negativamente na ecologia, no que se refere à diversidade de microrganismos atuantes no perfil do solo.

0 método pitfall permitiu indicar qual o nível de diversidade de meso e macrofauna que cada uso de solo apresenta, permitindo verificar similaridades populacionais ou diferenças da presença de maior frequência de mesmos organismos ou de organismos diversos. A riqueza de espécies foi mais precisa na diferenciação dos usos de solo.

\section{Agradecimentos}

Os autores agradecem aos alunos da disciplina de Microbiologia Agrícola/2015 que não mediram esforços e colaboraram de forma sobremaneira para a realização de trabalho.

\section{Referências}

Alexander, M. (1964). Biochemical ecology of soil microorganisms. Annual Review of Microbiology, 18, 217-253.

Almeida, L. M., Ribeiro-Costa, C. S. R., \& Marinoni, L. (2003). Manual de coleta, conservação, montagem e identificação de insetos. Ribeirão Preto: Holos, p.88.

Alvarenga, M. I. N., Siqueira, J. O., Davide, A. C. (1999). Teor de carbono, biomassa microbiana, agregação e micorriza em solos de Cerrado com diferentes usos. Ciência Agrotecnica, 23(3), 617-625.

Alves, M. V., Baretta, D., \& Cardoso, E. J. B. N. (2006). Fauna edáfica em diferentes sistemas de cultivo no Estado de São Paulo. Revista de Ciências Agroveterinárias, Lages, 5(1), 33-43.

Andreola, F. \& Fernandes, S. A. P. (2007). Microbiota do solo e qualidade ambiental. Instituto Agronômico CampinasSP, 21-37.

Antonini, S. R. C. (2004). Métodos de análises e monitoramento microbiológico em laboratório de destilaria. Araras: Centro de Ciências Agrárias, p.33. 
Antoniülli, Z. I., Conceição, P. C., Böck, V., Port, O., Silva, D. M., Silva, R. F. (2006). Método alternativo para estudar a fauna do solo. Ciência Floresta, 16, 407-417.

Aquino, A. M., Correia, M. E. F., Badejo, M. A. (2006). Amostragem da mesofauna edáfica utilizando funis de Berlese- Tüllgren modificado. Rio de Janeiro, Circular técnica Embrapa, p. 4.

Azevedo, V. F., Lima, D. A., Correia, M. E. F., Aquino, A. M. de Santos, H. P. dos. (2000). Fauna do solo em diferentes sistemas de plantio e manejo no Planalto Médio do Rio Grande do Sul. Santa Maria/RS: Fertbio. CD-ROM.

Barros, E., Curmi, P., Hallaire, V., Chauvel, A. \& Lavelle, P. (2001). The role of macrofauna in the transformation and reversibility of soil structure of an oxisol in the process of forest to pasture conversion, 100, p.193-213.

Begon, M., Harper, J. L., Townsend, C. N. (1996). Ecology: individuals, populations and communities. $3^{\text {th }}$ ed. Oxford, Blackwell Science, 1068.

Berg, B. (2000). Litter decomposition and organic matter turnover in northern forest soils. Forest Ecology and Management, 133(1), 13-22.

Brown, G. G. (2001). Diversidade e função da macrofauna no sistema edáfico agrícola. In: Congresso Brasileiro de Ciência do Solo, 28, 2001, Londrina. Anais. Londrina: Sociedade Brasileira de Ciência do Solo, p.56.

Bruyn, L. A. L. de. (1999). Ants as bioindicators of soil function in rural environments. Agriculture, Ecosystems and Environment, 74, 425-441.

Catanozi, G. (2011). Importância dos aspectos ecológicos na análise qualiquantitativa da macrofauna edáfica. Rev. Ibirapuera, (1), 42-52.

De Fede, K. L., Panaccione, D. G., Sextone, A. J. (2001). Characterization of dilution enrichment cultures obtained from size-fractionated soil bacteria by biologr community-level physiological profiles and restriction analysis of $16 \mathrm{~S}$ rDNA genes. Soil Biology and Biochemistry, Oxford, 33(11), 1555-1562.

Duelli, P., Obrist, M. K., Schmatz, D. R. (1999). Biodiversity evaluation in agricultural landscapes above-ground insects. Agriculture, Ecosystems and Environment, 74(13), 33-64

Edwards, C. A. (1991). The assessment of populations of soilinhabiting invertbrates. Agriculture, Ecosystems and Environment, 34, 145-176.

Filgueira, F. A. R. (2000). Manual de olericultura agrotecnologia moderna na produção e comercialização de hortaliças. Editora UFV, Viçosa, MG, p. 402.

Fitter, A. H., Atkinson, D., Read, D.J. \& Usher, M.B. (1985). Ecological interactions in soil: plants, microbes and animals. Blackwell Scientific Publications, 451.

Gassen, D. N. (1999). Os insetos e a fertilidade de solos. En: Curso sobre aspectos básicos de fertilidade e microbiologia do solo sob plantio direto. Resumos de palestras, 70-89.

Gomes, F. P. (1985). Curso de estatística experimental. São Paulo: Esalq, 467

Grayston, S. J., Grifftih, G. S., Mawdesley, J. L., Campebell, C. D. Bardgett, R. D. (2001). Accounting of variability in soil microbial communities of temperate upland grassland ecosystem. Soil Biology and Biochemistry, 33(4-5), 533551.

Gunn, A., Cherrett, J. M. (1993). The exploitation of food resources by soil meso and macro invertebrates. Pedologia, 37, 303-320.

Hungria, M., Araujo, R. S. (1994). Manual de métodos empregados em estudos de microbiologia agrícola. Brasília: EMBRAPA, p.442.

Lavelle, P. (1996). Diversity of soil fauna and ecosystem function. Biology Internship, 33(1), 3-16.
Lavelle, P., Blanchart, E., Martin, A., Toutain, F., Barois, I., Schaefer, R. (1993). A Hierarchical model for decomposition in terretrial ecosystems: application tosoils of the humid tropics. Biotropica, 25(2), 130-150.

Lavelle, P., Dangerfield, M., Fragoso, C., Eschenbrenner, V., LopezHernandez, D., Pashanasi, B., Brussaard, L. (1994). The relationship between soil macrofauna and tropical soil fertility, in the biological management of tropical soil fertility. In: Woomer, P. L., SwifT, M. J. Wiley Sayce, 137 169.

Loranger, G., Ponge, J. F., Blanchart, E., Lavelle, P. (1998). Influence of agricultural practices on arthropod communities in a vertisol (Martinique). Eur. Journal Soil Biology, 34(4),157-165.

Lourente, E. R. P., Silva, R. F. da, Silva, D. A. da, Marchetti, M. E., Mercante, F. M. (2007). Macrofauna edáfica e sua interação com atributos químicos e físicos do solo sob diferentes sistemas de manejo. Acta Scientiarum. Agronomy, 29(1), 17-22.

Madigan, M. T., Martinko, J. M., Dunlap, P. V., Clark, D.P. (2010). Microbiologia de Brock. 12 $\stackrel{\text { a }}{\text { Ed }}$. Editora Artmed, Porto Alegre, RS, 1.160 .

Moreira, F. M. S., Siqueira, J. O. (2002). Xenobióticos no solo. In: Moreira, F. M. S. \& Siqueira, J. O. Microbiologia e bioquímica do solo. Lavras: Editora UFLA, 243-284.

Moreira, F. M. S., Siqueira, J. O. (2006). Microbiologia e bioquímica do solo. $2^{\text {a }}$ ed. Lavras, UFLA. p.729.

Odum, E. P. (2008). Ecologia. In: Odum, E. P.; Barrett, G. W. (1983). Fundamentos de ecologia. Rio de Janeiro: Guanabara, 434. São Paulo: Cengage Learning, p. 612.

Paoletti, M. G. (1999). Using bioindicators based on biodiversity to assess landscape sustainability. Agriculture Ecosystem and Environment, 74, 1-18.

Peacock, A. D., Mullen, M. D., Ringelberg, D. B., Tyler, D. D., Hedrick, D. B., Gale, P. M., White, D. C. (2001). Soil microbial community responses to dairy manure or ammonium nitrate. Soil Biology and Biochemistry, 33, 1011-1019.

Poggiani, F., Monteiro Junior., E. S. (1990). Deposição de folhedo e retorno de nutrientes ao solo numa floresta estacional semidecídua, em Piracicaba (Estado de SP). In: Congresso Florestal Brasileiro. Campos do Jordão. Anais... Campos do Jordão: SBS/SBEF, 596-602.

Primavesi, A. (2002). Manejo ecológico do solo: a agricultura em regiões tropicais. São Paulo, Nobel, p.549.

Primack, R. B., Rodrigues, E. (2001). Biologia da conservação. Londrina, E. Rodrigues, 327.

Rodrigues, A. L., Nogueira, R. F., Barros, R., Degrande, P. E., Fernandes, M. G. (2003). Flutuação populacional de predadores sobre o solo da cultura do algodoeiro. In: Congresso Brasileiro de Algodão, 4. Goiânia. Resumos. Goiânia, Resumo 41. CD-ROM.

Rogers, B. F., Tate III, R. L. (2001). Temporal analysis of the soil microbial community along a toposequence in Pineland soils. Soil Biology and Biochemistry, Oxford, 33(10), 1389-1401.

Rosenberg, D. M., Danks, H. V., LehmkuhL, D. M. (1986). Importance of insects in environmental impact assessment. Environmental Management, 10(6), 773783.

Santos, A. A., Maia, L. D. M., Araujo, W. B. C., Silva, E. C. V., Lima, L. O., Moreira, A. N. (2012). Diversidade de artrópodes de solo em cultivo de videira e área nativa em Petrolina - PE. Disponível

em: <http://propi.ifto.edu.br/ocs/index.php/connepi/vii/paper /viewFile/5239/1742>. Acesso em: 12/04/2015.

Scolforo, J. R., Oliveira, A. D., Ferraz Filho, A. C., Mello J. G. (2008). Diversidade, equabilidade e similaridade no domínio da caatinga. In: Mello, J. M.; Scolforo, J. R.; Carvalho, L. M. T.(Eds). Inventário Florestal de Minas 
Gerais: Floresta Estacional Decidual - Florística, Estrutura, Similaridade, Distribuição Diamétrica e de Altura, Volumetria, Tendências de Crescimento e Manejo Florestal, 118-133.

Silva, C. F. (2005). Indicadores da qualidade do solo em áreas de agricultura tradicional no entorno do Parque Estadual da Serra do Mar em Ubatutaba (SP). Dissertação de Mestrado. Seropédica, UFRRJ, Instituto de Agronomia. p.93.

Silva, L. N., Amaral, A. A. (2013). Amostragem da mesofauna e macrofauna de solo com armadilha de queda. Revista Verde (Mossoró-RN - BRASIL), 8(5), 108 - 115.

Siqueira, J. O., Moreira, F. M. S., Grisi, B. M., Hungria, M., Araujo R. S. (1994). Microrganismos e processos biológicos do solo: Perspectiva ambiental. Empresa Brasileira de Pesquisa Agropecuária, Centro Nacional de Pesquisa de Arroz e Feijão, Centro Nacional de Pesquisa de Soja. EMBRAPA. p.142.

Soane, B. D., Ouwerkerk, C. V. (1994). Soil compaction problems in world agriculture. In: Soane, B. D., Ouwerkerk, C. V., eds. Soil compaction in crop production. Elsevier, 1-21.

Souto, P. T., Souto, J. S., Miranda, J. R. P., Santos, R. V., Alves, A. R. (2008). Comunidade microbiana e mesofauna edáficas em solo sob Caatinga no semi-árido da Paraíba. Revista Brasileira de Ciências do Solo, 32(32), 151-160.

Stork, N. E., Eggleton, P. (1992). Invertebrates as determinants and indicators of soil quality. American Journal of Alternative Agriculture, 7, 38-47.

Thomanzini, M. J., Thomanzini, A. P. B. W. (2000). A fragmentação florestal e a diversidade de insetos nas florestas tropicais úmidas. Circular Técnica. Rio Branco: Embrapa Acre, p. 21.

Tiedje, J. M., Cho, J. C., Murray, A., Treves, D., Xia, B., Ahou, J. (2001). Soil teeming with life: new frontiers for soil science. In: Rees, R. M.; Ball, B. C.; Campebell, C. D.; Watson, C. A. (Org.). Sustainable management of soil organic matter. Wallingford: CAB International, 393-412.

Toledo, L. O. (2003). Aporte de serrapilheira, fauna edáfica e taxa de decomposição em áreas de florestas secundária no município de Pinheiral, RJ. Dissertação (Mestrado em Ciências Ambientais e Florestais) - Instituto de Florestas, Universidade Federal Rural do Rio de Janeiro, Seropédica. p. 80.

Turco, R. F., Kennedy, A. C., Jawson, M. D. (1994). Microbial indicators of soil quality. In: Doran, J. W., Coleman, D. C., Bezdicek, D. F. \& Stewart, B. A., eds. Defining soil quality for a sustainable environment. Madison, Soil Science Society of America, 73-90.

Villani, M. G., Wright, R. J. (1990). Environmental influences on soil macroarthropod behavior in agricultural systems. Annual Review Entomology, 35, 249.

Wardle, D. A. (1992). A comparative assessment of factors witch influence microbial biomass carbon and nitrogen levels in soil. Biological Reviews, 67(3), 321-358.

Whittaker, R. H. (1977). Evolution of species diversity in land communities. In: Hecht, M.K. Steere, W. C. \& Wallace, B. Evolutionary biology, 10, 250-268. 